\title{
Coronary stent stenosis in acute myocardial infarction
}

\author{
Marcelo Rodrigues Bacci, ${ }^{1}$ Janaina Aparecida Boide Santos, ${ }^{2}$ \\ Leonardo Fernando Ferrari Nogueira ${ }^{2}$
}

'Department of General Practice, Faculdade de Medicina do ABC, Santo André, Brazil

${ }^{2}$ Department of Cardiology, Faculdade de Medicina do ABC, Santo André, Brazil

Correspondence to Prof Marcelo Rodrigues Bacci, mrbacci@yahoo.com
To cite: Bacci MR, Santos JAB, Nogueira LFF. $B M J$ Case Rep Published online: [please include Day Month Year] doi:10.1136/ bcr-2013-009790

\section{SUMMARY}

Acute myocardial infarction (AMI) represents one of the major mortality causes in the world. Treatment of AMI is widely known; however, in developing countries some medications are not so easily available yet. We present a case of a 49-year-old black male patient who suffered an AMl and 2 weeks after stent angioplasty evolved to a new ischaemic episode with a stent thrombosis. The patient did not use the prescribed medications.

\section{BACKGROUND}

Stent thrombosis is the most feared complication in percutaneous coronary interventions. Although its incidence is less than $1 \%,{ }^{1}$ it is responsible for impressive acute cases. Stent thrombosis leads to myocardial infarction (MI) in more than $60 \%$ of the cases with mortality rate of around $30 \% .^{2}$ Its gravity promoted great evolutions in procedure performance and drug therapy after intervention in order to reduce its occurrence. We present a case of a patient with acute myocardial infarction that evolved to in-stent stenosis because the patient did not adhere to the medication regimen.

\section{CASE PRESENTATION}

A black man, aged 49 , was admitted to the emergency department of São Bernardo do Campo Hospital Complex with retrosternal pain of $3 \mathrm{~h}$ duration. He presented with profuse cold sweats at extremities and nausea. His blood pressure was $140 / 90 \mathrm{~mm} \mathrm{Hg}$, heart rate $67 \mathrm{bpm}$ and respiratory rate 14 breaths $/ \mathrm{min}$ with pulse oximetry $96 \%$ in ambient air. A 12-lead ECG was carried out and the alterations are shown in figure 1.

An acute extensive anterior wall MIs with positive ST elevation was diagnosed. Treatment with tenecteplase was started along with the administration of enoxaparin, acetylsalicylic acid and clopidogrel, following the American Heart Association guidelines. ${ }^{3}$

The patient had a medical history of hypertension and smoked 20 cigarettes a day for 30 years. He had previously suffered two MIs, the last one 2 weeks prior to the current event. In this last event he underwent an angioplasty with stent implantation in the anterior descending artery. $\mathrm{He}$ reported that he had not used the prescribed medication of clopidogrel, carvedilol, enalapril and acetylsalicylic acid.

First laboratorial exams showed creatine phosphokinase $\mathrm{MB}$ of 11 and creatine phosphokinase of 80 with levels of troponin I qualitatively positive. The other variables were normal.

\section{OUTCOME AND FOLLOW-UP}

The cine coronary angiography the patient underwent during the first event, 2 weeks before his admission, was requested so that the previous lesion could be analysed. There was a lesion of $70 \%$ in the proximal segment and $90 \%$ in the distal segment of the anterior descending artery (figure 2).

The present cine coronary angiography revealed a residual thrombosis in the stent implanted in the proximal segment of the anterior descending artery (figure 3). Subacute thrombosis in the stent was controlled with a conventional stent angioplasty, with TIMI flow 3.

Doppler-colour bi-dimensional echocardiography revealed an important acinesia in the apicoanteroseptal regions, with ejection fraction estimated at $37 \%$. His left ventricle showed discreet dilation and concentric hypertrophy. He was discharged from hospital 7 days after the first event.

\section{DISCUSSION}

Stent thrombosis always occurs as an acute coronary syndrome after percutaneous angiographic revascularisation, confirmed by a new angiographic study. Its classification is related to the time it occurs in relation to the procedure: early, when it occurs in the first 30 days after the stent implantation (acute, in the first $24 \mathrm{~h}$ and subacute, between 1 and 30 days); late, when it occurs between 31 days and 12 months; very late, when it occurs after 12 months.

Stent thrombosis occurrence is multifactorial, but its physiopathology starts with the aggression of the stent structure to the endothelium and the inflammatory process that is triggered.

In the first $24 \mathrm{~h}$ a deposit of platelets and fibrins starts along with the infiltration of neutrophils. The inflammation is associated with tunica media injury and the lipid core of the treated plaque when penetrated by the stent structure. It is in this phase that the formation of platelet-rich thrombus may occur, promoting an early stent thrombosis which is more related to the difficulties met during the procedure, like the inadequate expansion of the stent or its smaller size than the treated plaque. ${ }^{12}$

The inflammatory process stimulates the migration and proliferation of smooth muscle cells that triggers the re-epithelisation process through neointimal hyperplasia. It starts 2 weeks after the stent implantation and the total epithelisation occurs in around 3 months. ${ }^{2}{ }^{3}$ This causes coronary geometric alterations with intra stent and peri stent blood 


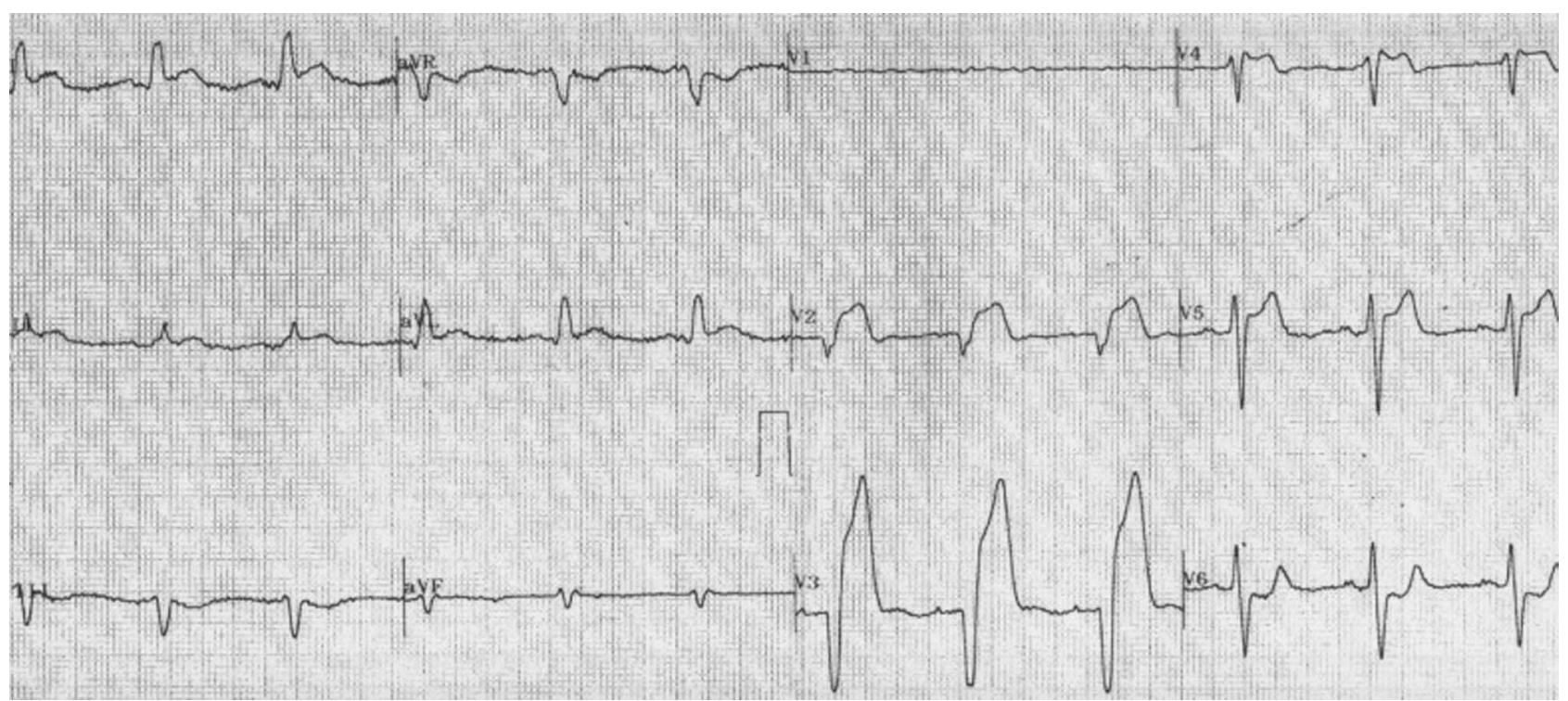

Figure 1 ECG showing ST elevation.

flow changes and with regions of higher and lower pressures of endothelial shear stress. Those regions of lower pressure of shear stress promote the worsening of the endothelial dysfunction and those of higher pressure of shear stress favour the platelet activation. ${ }^{4}$ It is in this scenario that the double antiplatelet therapy is proved to be of great importance.

The neointimal hyperplasia, when exaggerated, promotes the gradual intrastent obstruction and, when symptomatic, it is known as in-stent stenosis, another complication of the pericutaneous interventions. At this point the stent thrombosis falls within the late classification and it is associated with the lesion severity that the stent caused (bifurcations, long or multiple stents). ${ }^{45}$

In order to reduce the in-stent stenosis incidence, drug-eluting stents were designed. They reduce the neointimal hyperplasia; therefore, re-epithelisation occurs later and in-stent stenosis decreases in up to $70 \%$ of the cases. ${ }^{5}$ On the other hand, a new inflammatory process induced by the polymers of the drug-eluting stent structure are be observed. When associated

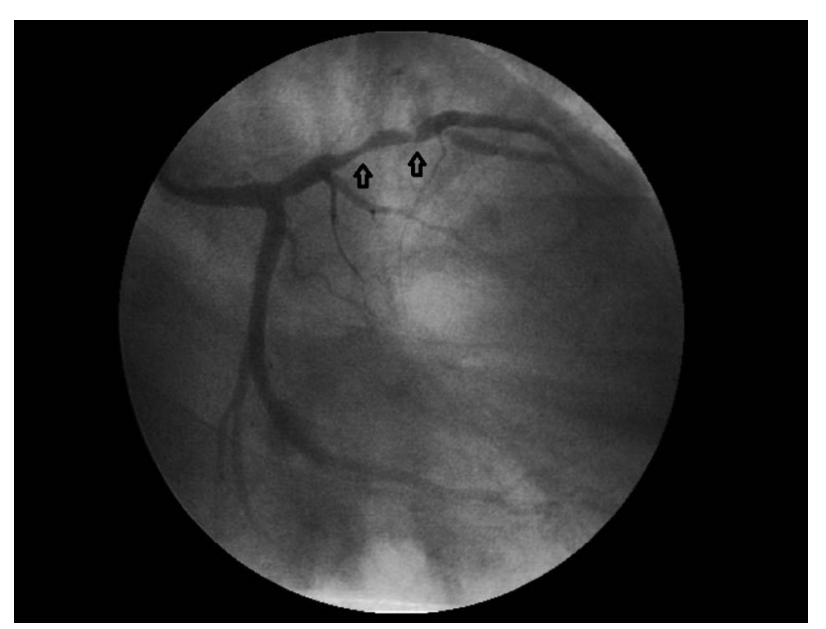

Figure 2 Black arrows showing critical arterial obstruction of the descendent anterior artery. with the late re-epithelisation, this new process made the late stent thrombosis events to increase.

Thus, the risks for the occurrence of stent thrombosis depend on the patient, the atherosclerotic lesion, the implantation procedure and the antiplatelet therapy. All eyes are turned to these factors in the intent to prevent the stent thrombosis.

Factors of the patient and the lesion are unchangeable. However, they point to those patients who are more susceptible to thrombosis. One-quarter of the patients with acute coronary syndrome are diabetic and are twice more likely to develop stent thrombosis. ${ }^{6}$ In such groups, the control of risk factors for cardiovascular disease, the choice of the best revascularisation therapy with the adequate technique and the antiplatelet therapy with the ideal duration are paramount factors.

New generation drug-eluting stents have biodegradable polymers with better biocompatibility. They are capable of increasing the neogenisis through stem cells differentiation in endothelial cells rather than in smooth muscle cells. ${ }^{5}$

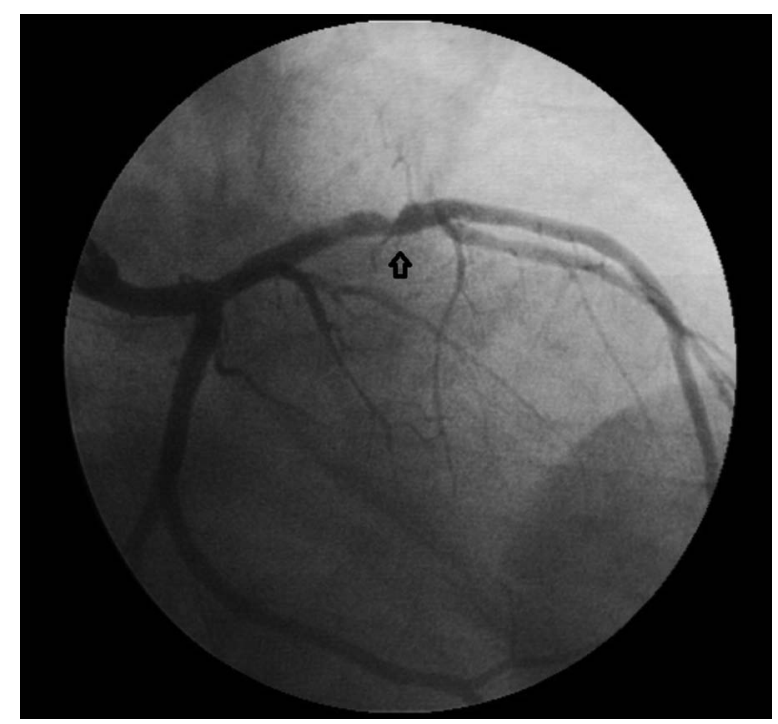

Figure 3 Black arrow showing the obstruction of the stent previously placed. 
The use of higher doses of clopidogrel or more potent antiplatelets (prasugrel and ticagrelor) have not shown benefits yet. Although they decrease the chance of stent thrombosis, they lead to higher rates of excessive bleeding without any remarkable improvement in results. ${ }^{27}$

Duration of the double antiplatelet therapy is still the most important point to be considered. A higher risk of stent thrombosis is observed when clopidogrel administration is interrupted before 6 months with drug-eluting stents, and before 4 weeks with bare-metal stents. Yet, the use for respectively 12 and 6 months is ideally recommended. ${ }^{2} 37$

In the presented case however, the non-adherence to the treatment was the main factor of the complication. The doctorpatient relationship is the best way to guarantee patients' adherence to medication regimen, including the antiplatelet therapy. The best way to prevent stent thrombosis with a non-adherence risk patient is with the reinforcement of this relationship

\section{Learning points}

- It is of great importance that the use of clopidogrel be reinforced for patients who undergo stent angioplasty.

- There is no predetermined time for a subsequent reinfarction. However, the odds are higher for bare metal stents in the first 30 days after the initial event.

- Patients with clopidogrel intolerance should use another antiplatelet agent as an alternative, like ticlopidine or ticagrelor. The use of more than one antiaggregant agent is highly recommended.
Contributors MRB conducted the case report, LFFN and JABS were involved in the diagnosis of the patient. MRB also wrote the case report, LFFN wrote the discussion part and JABS was involved in image selection.

Competing interests None.

Patient consent Obtained.

Provenance and peer review Not commissioned; externally peer reviewed.

\section{REFERENCES}

1 Aoki J, Lanski AJ, Mehran R, et al. Early stent thrombosis in patients with acute coronary syndromes treated with drug-eluting and bare metal stents: the acute catheterization and urgent intervention triage strategy trial. Circulation 2009;119:687-98.

2 Motovska Z, Knot J, Widimsky P. Stent thrombosis - risk assessment and prevention. Cardiovas Ther 2010;28:92-100.

3 Antmann EM, Anbe DT, Armstrong PW, et al. ACC/AHA guidelines for the management of patients with ST-elevation myocardial infarction-executive summary. Circulation 2004;110:588-636.

4 Koskinas KC, Chatzizisis YS, Antoniadis AP, et al. Role of endothelial shear stress in stent restenosis and thrombosis: pathophysiologic mechanisms and implications for clinical translation. J Am Coll Cardiol 2012;59:1337-49.

5 Inoue $\mathrm{T}$, Croce $\mathrm{K}$, Morooka $\mathrm{T}$, et al. Vascular inflammation and repair: implications for re-endothelization, restenosis, and stent thrombosis. J Am Coll Cardio: C Inter 2011;4:1057-66.

6 Wiviott SD, Braunwald E, Angiolillo DJ, et al. Greater clinical benefit of more intensive oral antiplatelet therapy with prasugrel in patients with diabetes mellitus in the trial to assess improvement in therapeutic outcomes by optimizing platelet inhibition with prasugrel-thrombolysis in myocardial infarction 38. Circulation 2008;118:1626-36.

7 Kirtane AJ, Stone GW. How to minimize stent thrombosis. Circulation 2011:124:1283-87.

Copyright 2013 BMJ Publishing Group. All rights reserved. For permission to reuse any of this content visit http://group.bmj.com/group/rights-licensing/permissions.

BMJ Case Report Fellows may re-use this article for personal use and teaching without any further permission.

Become a Fellow of BMJ Case Reports today and you can:

- Submit as many cases as you like

- Enjoy fast sympathetic peer review and rapid publication of accepted articles

- Access all the published articles

- Re-use any of the published material for personal use and teaching without further permission

For information on Institutional Fellowships contact consortiasales@bmjgroup.com

Visit casereports.bmj.com for more articles like this and to become a Fellow 